\title{
Consumption and the Trade Cycle
}

$\mathrm{A}^{\mathrm{T}}$ T the recent meeting of the British Association at York, Prof. Lionel Robbins, professor of economics in the University of London, in a paper read before Section $\mathrm{F}$ (Economic Science and Statistics) on "Consumption and the Trade Cycle", made a critical examination of the 'Social Credit' proposals associated with the name of Major C. $\mathrm{H}$. Douglas. The following is a short summary of this part of his argument.

Major Douglas bases the diagnosis on which his constructive proposals depend on a survey of factory costing. Consider any article of factory manufacture, he says : a nut and bolt, for example. Part of its cost consists of wages, salaries, etc. ; but part consists of raw material charges, factory upkeep and similar 'overheads'. The sums distributed as income, therefore, are not sufficient to purchase current output. What is true of one factory is true of all. It follows, therefore, that, throughout the entire economic system, there is a continuous deficiency of income to purchase the product; a deficiency which, if not made good by the continuous issue of paper money, must necessarily lead to chronic bankruptcy and confusion.

Now it is perfectly true, as Major Douglas urges, that the sums distributed as ultimate incomes-wages, salaries, rents, etc.-are insufficient to purchase the gross product of industry. But so far from this being a cause of industrial crisis, it is in fact an essential condition of the smooth functioning of the economic system.

This can easily be demonstrated if a capitalistic system which is in stationary equilibrium (that is, a system in which no saving is taking place) be examined with the view of discovering the conditions of the persistence of equilibrium. It should be clear that, of the total volume of payments being made at any one moment, only a comparatively small proportion is being made for the final product. The remainder goes to facilitate the movement of goods between the different earlier stages of production. That is to say, at the same time as money is being spent on bread by the wage-earner-the ultimate consumer-the baker is spending money on flour to replace the bread, the miller is spending money on wheat to replace the flour, and so on and so forth.

In order that such a system should continue in equilibrium it is necessary that these payments should be made; yet they do not go to the recipients of ultimate income. They are costs but they are not net income. In any computation of the net value produced during the unit period, such as that made in the British census of production, they will be set off one against the other. At the end, when they are thus offset, we get the value of the goods available for consumption ; and for equilibrium to be preserved, it is necessary that the incomes of the factors of production should correspond only to this. In order that the same structure of production may persist from No. 3288, VoL. 130] period to period, those payments in the gross income (to use the classical term) which cancel out must be made. It is undesirable, therefore, that a state of affairs other than that which Major Douglas describes should actually come to exist.

This conclusion becomes even more forcible if it be supposed that what Major Douglas thinks ought to happen has actually occurred. Suppose that, the quantity of money remaining the same, ultimate incomes were to be raised so as to equal the value of the gross product. What would this imply? Simply that the whole fund of free capital (amortisation quotas and working capital) had been turned into ultimate income. What would happen ? Prices of ultimate commodities would probably rise ; but prices of intermediate products, raw materials and fixed plant, would collapse. There would be no free capital to buy them with; there would occur all the symptoms of extreme crisis. Of course, such a state of affairs is not likely to occur. But, if wages are above the equilibrium point, it is possible for something disquietingly like it to begin to make its appearance. The illustration should at least make clear the fundamental point overlooked by Major Douglas: that once there exists what may be called many-stage production, it is undesirable that the money income in a given period should be equal to the value of the gross product of that period. Only in a system of hand-to-mouth, or single stage, production is it compatible with the requirements of equilibrium that the net income and the gross income should be identical.

Thus in the case most favourable to Major Douglas - the completely stationary state-his argument breaks down completely. If real accumulation is to take place - that is, if the system is to be progressive - then the refutation applies a fortiori. For, in such circumstances, not only must the gross income exceed the amount spent on consumption goods available by the difference between net income and gross income ; it must also contain a quantity equivalent to the amount of net saving. If accumulation is to take place, there must be abstention from using all the productive power available to produce current real income at a constant rate. This involves spending some of the current money income on goods which only give rise to real income in the future.

In subsequent sections of his paper, Prof. Robbins argued that not only is there no reason to attribute industrial depression to a deficiency of consumption, but also that there is, on the contrary, considerable reason to believe that the coming of depression is due to the fact that consumption has become too high for capital extensions already embarked upon to be profitably carried through. Recent investigations, he argued, seem to make it more and more probable that booms are due to forced saving brought about by inflation of credits; and that the collapse of the 
boom is due to the exhaustion of this process. It is truer to say that the depression comes because consumption is too urgent than because it is not urgent enough. We do not "starve in the midst of plenty" because we do not demand enough; we starve because, having forced the tree of prosperity, we seek to pluck its fruits before they are ripe.

It may be added that a more elaborate critique of proposals substantially similar to those of Major Douglas will be found in "The Paradox of Saving" by F. A. von Hayek in Economica of May, 1931.

\section{Canadian Polar Year Expedition, 1932-33}

CANADA'S part in the International Polar Year 4 is to establish a chain of stations not more than $1400 \mathrm{~km}$. apart, connecting Greenland with the United States station at Fairbanks, Alaska, and to provide special magnetic equipment at Meanook, the nearest permanent magnetic observatory to upper air observations, with twice-daily pilot balloon ascents, will be continued throughout the year. The auroral programme will consist of visual observations at specified hours, and as opportunity occurs photographs will be taken. The station is in charge of Mr. J. E. Lilly of Acadia University,

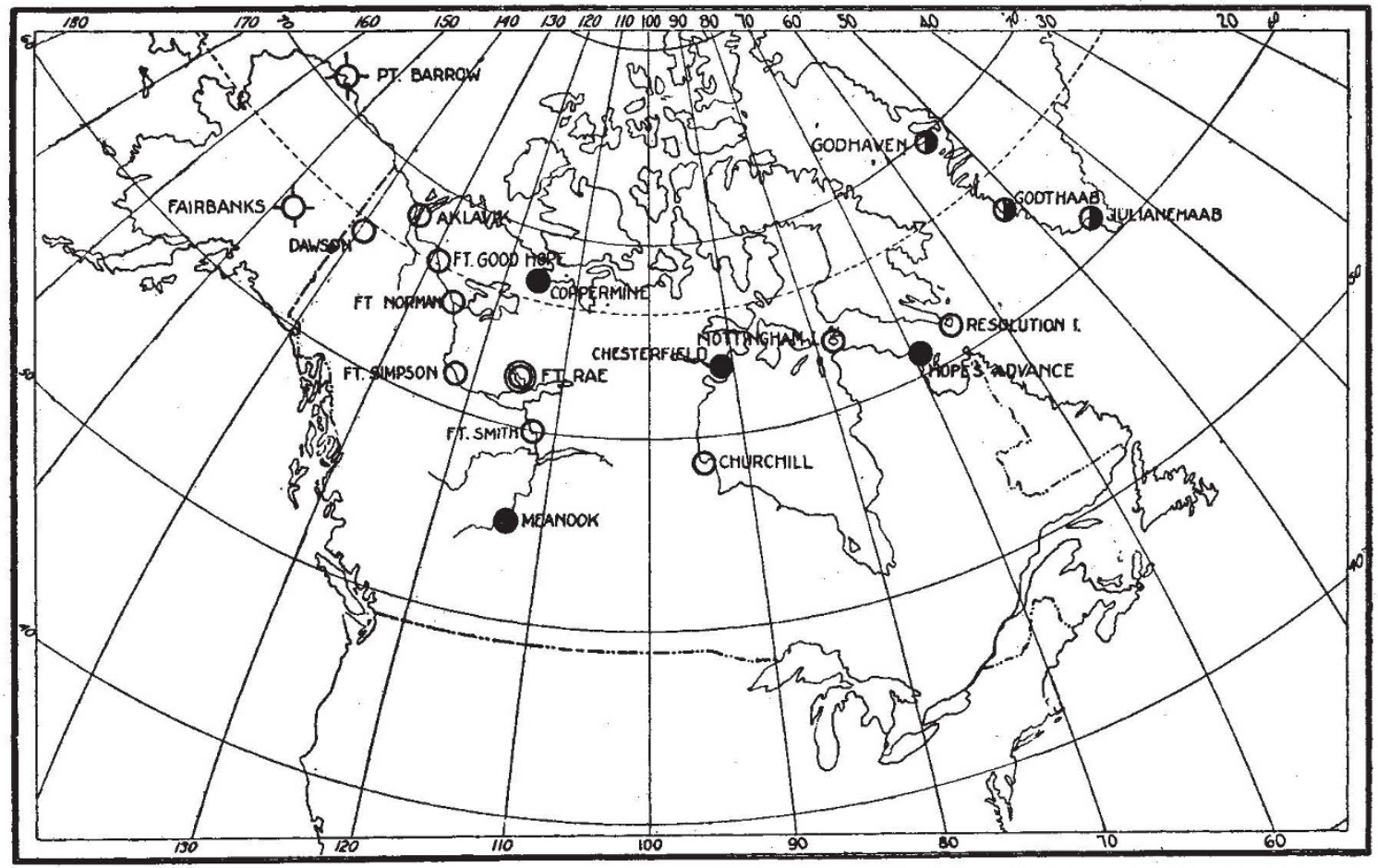

FrG. 1.-International Polar Year stations in North America and Greenland. $\bigcirc$, Canadian telegraph stations;, Canadian Polar Year stations specially equipped and manned; (-), British expeditions;- - United States stations specially equipped and manned; (1) Danish stations.

the north magnetic pole. For this purpose three expeditions have been sent out, the first to Cape Hope's Advance in Hudson Straits, $1000 \mathrm{~km}$. from the nearest station in Greenland; Chesterfield Inlet on the west coast of Hudson's Bay, $1200 \mathrm{~km}$. away; and finally Copper Mine on the Coronation Gulf, $1300 \mathrm{~km}$. to the west, and a little more than $1500 \mathrm{~km}$. from Fairbanks, Alaska. The accompanying map (Fig. 1) shows the position of these stations, as well as the regular meteorological stations in northern Canada. It may also be mentioned here that at these stations there are wellequipped wireless stations, so that communication can always be obtained with the outside world.

At Cape Hope's Advance, lat. $61^{\circ} 5^{\prime}$ N., long. $69^{\circ} 33^{\prime} \mathrm{W}$., complete surface meteorological and assisted by the radio operators at the station. Cape Hope's Advance is situated on a fairly high promontory extending out into Hudson Straits, and at times very high wind velocities are obtained, the most notable being above one hundred and thirty miles an hour for one hour, and above one hundred miles an hour for several hours continuously. The temperature averages about fifteen below zero in January, while in the middle of summer it has exceeded $70^{\circ}$. Rainy days are frequent in June and August, frequently accompanied by fog with snow in any month of the year.

Chesterfield Inlet.-The principal Canadian station is at Chesterfield Inlet, lat. $63^{\circ} 45^{\prime} \mathrm{N}$., long. $91^{\circ} 50^{\prime}$ W., about four hundred and fifty miles from the north magnetic pole, this being the

No. 3288, Vol. 130] 